\title{
Design of the Complex Super High-Rise Architectural Structure of Fuyou Twin Towers in Binzhou City
}

\author{
Xuping Zhu ${ }^{1}$, Yuanqing Wang ${ }^{1}$ and Lin $\mathrm{Yu}^{2}$ \\ ${ }^{1}$ Department of Civil Engineering, Tsinghua University,China \\ ${ }^{2}$ China Western Power Industrial Co., Ltd., Zigong, Sichuan 643001
}

\begin{abstract}
Based on the design of the complex super high-rise architectural structure of Fuyou Twin Towers in Binzhou City, this paper introduces the principles for structural layout, structural calculation and determination of key parts of the project and gives the relevant calculation and analysis results. The calculation results show that multiple aseismic behavior indexes of the project under frequent seismic action can meet the requirements of the relevant codes, and the structure can meet the seismic fortification criterion of "no damage in minor earthquakes", "mendable in moderate earthquakes" and "no crash in major earthquakes". The design ideas of the project can be used as references for engineering designers.
\end{abstract}

Keywords-engineering antiseismic design; structural design; high-rise buildings; complex structure

\section{Description of the Project}

Fuyou Twin Towers in Binzhou City is a complex building integrating a five-star hotel, a leisure club and office and residential functions and will become the landmark building in Binzhou City after it is completed. With a total floor space of $59,418 \mathrm{~m} 2$, the project is a high-rise twin-tower complex structure with a large base. The main building is $121.2 \mathrm{~m}$ high and has 33 floors, the 1st 4th floors are the annex to the hotel, the part above the 4th floor is the twin towers, and there is a banquet hall that can accommodate 1,000 guests on the 4th floor. It is required that there should be no structural columns within the space of $29.9 \mathrm{~m} \times 57.9 \mathrm{~m}$ and a tennis court and a swimming pool should be built on the roof of the large banquet hall. Building 1 has 33 floors and is the apartment office building with a total height of 121.2m; Building 2 has 31 floors and is the main hotel building, with a total height of $118.6 \mathrm{~m}$. The reference wind pressure of the building is set as $0=0.55 \mathrm{kN} / \mathrm{m} 2$, its ground roughness is Class $B$, its seismic fortification intensity is 7 degrees, its designed earthquake grouping is a group, and its site classification is Class II.

\section{OVER-LIMIT RECOGNITION OF STRUCTURE AND MEASURES TO BE}

\section{A Over-limit Recognition}

Due to the complex functions of the building, to meet the demand of a large base, the frame-supported shear wall structure system is adopted, the transfer floor is located on the 4th floor, and beam-type transfer which belongs to high-level transfer is used. The part above the transfer floor is the twin-tower structure, the main hotel building has a staggered structure, and the main building is $121.2 \mathrm{~m}$ high, so the project is a staggered, out-of-code ultra high-rise structure.

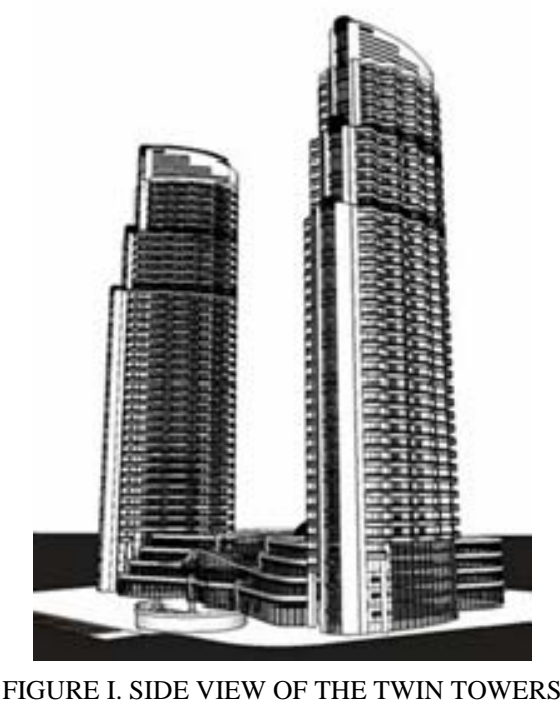

\section{B Staggered Floor}

As different functional areas should have different floor heights and there should be skip and staggered floors in the same functional area, the floor heights of the project are very complicated. To realistically simulate the changes in floor height, the two main buildings above the annex are defined as multiple towers by SATWE while building the structural analysis model so as to address the problem of different floor heights of the two main buildings. For structural staggered floors in the same tower, the model was built based on the actual floor height, staggered floors were set as elastic diaphragms, and the in-plane stiffness of slabs was calculated truly.

\section{Plane Irregularity}

In the structural layout, the two main towers of the project are arranged at the right and left ends, rigid steel reinforced concrete columns, shear walls and other main load-bearing and lateral-force-resisting members are arranged at both ends of the buildings; The middle part of the building consists of the lobby, the banquet hall that can accommodate 1000 guests and other ancillary functional facility areas of the hotel. For the standard height of this part from the bottom to the transfer floor, structural arrangements should be large or ultra large spaces, and there should be no shear walls or columns. Thus the lateral-force-resisting members of the part below the transfer floor are mainly concentrated at both ends of the annex, while the lateral-force-resisting stiffness of the middle part is 
relatively small. The banquet hall is located on the 4th floor in the middle part of the annex, it is impossible to divide the building into three sections, so overall force analysis was carried out for the entire building without aseismatic joints, and separate calculation was carried out for the two main buildings (without the intermediate annex) respectively, and the three models should meet the requirements of the national codes.

\section{High-level Transfer}

Structures with high-level transfer floor belong to out-of-code structures as specified by the prevailing design codes for relevant structures. In the elastic working stage of structure, the horizontal earthquake force borne by frame-supported shear walls above the transfer floor and ground shear walls below the transfer floor is roughly equal, the shear force below the transfer floor is mostly borne by ground shear walls, and now the horizontal shear force borne by frame-supporting columns is very small. In the elastoplastic working stage, cracks will first appear on ground shear walls or plastic hinges will enter the elastoplastic working state. The concrete presentation is that the horizontal lateral resisting stiffness of ground shear walls has reduced, the horizontal earthquake shear force borne by ground shear walls is transferred to frame-supported columns, and now frame-supported columns become the weak parts in the entire structure. This is especially true for structures with high-level transfer floor. Therefore, when designing structures with high-level transfer floor, we should pay more attention to aseismic behavior and ductility design of frame-supporting columns.

The following reinforcing measures are adopted in this project: (1) increase the wall thickness of core tube and ground shear wall so as to increase the horizontal shear-bearing capacity of core tube and ground shear wall; (2) use steel reinforced concrete frame-supported columns to improve ductility and other aseismic behaviors of frame-supported columns; (3) adjust the calculation model to ensure that there is no sharp change in the relative angular displacement above and below the transfer floor and adjacent floors of the structure under the action of horizontal seismic loads and that the horizontal deformation curve is as smooth as possible.

\section{E Prestressed Steel Reinforced Concrete Beam}

In this project, prestressed concrete structure is used for beams with span of $22 \mathrm{~m}$, and prestressed steel reinforced concrete is used for roof beams with span of $32 \mathrm{~m}$. The concrete methods are as follows:

(1) For prestressed concrete beams with span of $22 \mathrm{~m}$, the cross section is $600 \times 1,600,29$ prestressed strands are used, among which 21 strands are bonded and 8 strands are unbonded. The unbonded strands are used only to improve crack resistance and are not involved in strength calculation.

(2) For prestressed steel reinforced concrete beams with span of $32 \mathrm{~m}$, the cross section is $650 \mathrm{mmx} 1,650 \mathrm{~mm}$, I-shaped steel is used, the height of steel girder web is $1,450 \mathrm{~mm}$, and the thickness of steel plate is $18 \mathrm{~mm}$; the width of flange is $450 \mathrm{~mm}$, and the thickness of steel plate is $32 \mathrm{~mm}$. As the strength requirements have been met, 22 unbonded prestressed strands are used only to improve crack resistance and are not involved in strength calculation.

(3) The mixed configuration of 1860 bonded low relaxation steel strands and unbonded steel strands is used. When the concrete strength reaches C35, start stretching, and the stretching control stress is $1,400 \mathrm{MPa}$, with dual control and overstretching of $3.2 \%$. Wedge anchors are used for end anchorage, and extruding anchors are used for fixed-end anchorage.

\section{STRUCTURE CALCULATION AND ASEISMIC TECHNICAL MEASURES}

\section{A Overall and Local Structure Analysis with Software}

In this project, SATWE and PMSAP are used for overall calculation, and ETABS is used for reviewing. FEQ is used for reviewing the reinforcement for transfer beams and frame-supported columns, PREC is used for calculating the reinforcement for prestressed elements, and PMSAP is used for elasto dynamic time-history analysis.

\section{B Main Aseismic Technical Measures Used in This Project}

(1) Shear walls from the elevation of the positive and negative zero to the two floors above the transfer floor are defined as reinforcing area, and the reinforcement ratio of distribution bars is also taken as $0.3 \% \sim 0.4 \%$, and some longitudinal bars of frame-supported columns rise to the shear walls of the upper floor.

(2) Coupling beams are mainly low coupling beams. Long beams mainly for bending and deformation are regarded as ordinary frame beams. To ensure the ductility of coupling beams for energy-consuming elements, the design principles of "strong column and weak beam" and "strong compression and weak tension" are realized in auxiliary calculation and architecture, and additional concealed supports are set to reinforce some coupling beams.

(3) Frame-supported beams can better work together with upper walls and can be designed according to the relevant codes. For safety sake, their shear-compression ratio can be properly controlled and taken as $0.10 \sim 0.15$ according to the design method for transfer girders.

(4) Two-layer two-way reinforcement is used for slabs of transfer floor, the reinforcement ratio in each direction should be no less than $0.25 \%$; the slab thickness of large roof is designed as $160 \mathrm{~mm}$, with two-layer two-way reinforcement, and the reinforcement ratio should meet the computing requirements and be no less than $0.25 \%$.

(5) This project belongs to a structure with plane and vertical irregularities, so in structural layout, vertical members should be arranged as uniformly as possible to reduce the overall torsion effect of the structure.

(6) The frame-supported floor and all floors below are the weak floors of the structure and must be strengthened conceptually during the design to improve the aseismic behavior and ductility of frame-supported columns. For example, the moment and shear force of frame-supported columns and ground shear walls can be adjusted, the axial compression ratio of frame-supported columns is controlled 
based on 0.55 , the reinforcement ratio of longitudinal steel bars of frame-supported columns is increased $1.20 \% \sim 1.40 \%$, and the stirrup containing rate by volume of stirrups of frame-supported columns is increased to $1.50 \%$. When designing the distribution bars of shear walls, the reinforcement ratio of distribution bars is taken as $0.3 \% \sim 0.4 \%$ in view of the fact that this project is a structure with high-level transfer so as to improve the aseismic behavior and ductility of ground shear wall and reduce the burden of concealed columns at the ends.
C Main Results of Structural Calculations

\section{1) Analysis results of satwe and pmsap}

The main calculation results of SATWE and PMSAP is shown in Table 1.

TABLE I. MAIN CALCULATION RESULTS OF SATWE AND PMSAP

\begin{tabular}{|c|c|c|c|}
\hline Software & & SATWE & PMSAP \\
\hline \multirow{4}{*}{ Period } & $\mathrm{T} 1$ & $2.25(100 \%$ (translational motion) & $2.384(100 \%)$ \\
\hline & $\mathrm{T} 2$ & $2.123(100 \%$ (translational motion) & $\begin{array}{c}2.051(100 \% \text { (translational } \\
\text { motion) }\end{array}$ \\
\hline & $\operatorname{Tn}$ & $1.511(80 \%$ torsion $)$ & $1.882(100 \%$ torsion $)$ \\
\hline & $\mathrm{Tn} / \mathrm{T} 1$ & 0.67 & 0.79 \\
\hline Interlaminar Maximum & $\mathrm{x}$ direction & $1 / 1001$ & $1 / 1012$ \\
\hline Displacement angle & y direction & $1 / 1334$ & $1 / 1184$ \\
\hline Maximum level & $\mathrm{x}$ direction & 1.31 & 1.21 \\
\hline \multirow{3}{*}{$\begin{array}{l}\text { Displacement and floor } \\
\text { Average interlaminar } \\
\text { displacement } \\
\text { Displacement ratio }\end{array}$} & & Occasional eccentric:1.36 & Occasional eccentric:1.25 \\
\hline & y direction & 1.28 & 1.25 \\
\hline & & Occasional eccentric:1.39 & Occasional eccentric:1.38 \\
\hline \multirow{2}{*}{$\begin{array}{c}\text { Shear-weight ratio } \\
\qquad / \%\end{array}$} & $\mathrm{x}$ direction & 2.4 & 2.4 \\
\hline & y direction & 2.87 & 3.11 \\
\hline
\end{tabular}

(1) The $1^{\text {st }}$ and $2^{\text {nd }}$ periods are both translational periods, and the ratio of the $3^{\text {rd }}$ period to the $1^{\text {st }}$ period is less than 0.90 , which meets the requirements of the design code for high-rise buildings. This shows that the structure's arrangement is reasonable.

(2) The ratio of maximum floor displacement of the structure under the action of calculated earthquake and bi-directional earthquake to the average displacement of the floor is less than the limit value of 15 times, which meets the requirements of the code. The maximum displacement meets $1 / 800$ as specified by the code and is close to the limit value specified by the code. The displacement in $\mathrm{X}$ and $\mathrm{Y}$ directions are similar, showing that the structure has reasonable overall stiffness and is arranged evenly.

(3) The lateral stiffness ratios of the upper and lower transfer floors of this project calculated based on the formula as specified by the code meet the requirements of the code.

(4) Comparing the calculation results of the two programs of SATWE and PMSAP, inter-floor displacement and seismic force and other indicators are similar, and no abnormality was found, showing that the calculation results are reliable and can be used as the design basis.

2) Results of elastic dynamic time-history analysis.
According to the characteristics of the structure, we have selected two natural waves and two artificial waves and carried out dynamic elastoplastic time-history analysis. The results show that the shear force at the bottom of the structure calculated based on each time- history curve is not less than $65 \%$ of the shear force at the bottom obtained based on the mode-superposition response spectrum method, and the average shear force at the bottom of the structure calculated based on multiple time- history curves is not less than $80 \%$ of the shear force at the bottom obtained based on the mode-superposition response spectrum method. These meet the requirements of the code. According to the floor displacement angle envelope curve, displacement mutation occurs on the $5^{\text {th }}$ and $22^{\text {nd }}$ floors of the structure. The $5^{\text {th }}$ floor is the transfer floor of the structure, and the $22^{\text {nd }}$ floor and those above are the positions where floor height changes occur, showing that the calculation results are consistent with the functional changes of the building, reflecting the actual force bearing of the project. In response to such displacement mutation, we have adjusted the number and thickness of shear walls and the height of coupling beams for the $4^{\text {th }} \sim 6^{\text {th }}$ floors and the $20^{\text {th }} 23^{\text {rd }}$ floors to control interlaminar stiffness and increased the reinforcement ratio of shear walls to reinforce shear walls. 


\section{CONCLUSIONS}

(1) The code will rarely take targeted measures for such interlaminar stiffness mutation of frame-supported structures except controlling the stiffness ratio of the upper and lower floors (for example, not greater than 2). In fact, the presence of frame-supported floors may lead to re-distribution of internal forces between walls and columns, so apart from reinforcing frame-supported columns, we still need to reinforce other members in the same floors such as part of shear walls according to their force bearing so as to enhance the ductility of the structure.

(2) Building function and shape requirements make this project a complex high-rise structure, but due attention has been weak parts and important links in its design and appropriate analysis calculation and reinforcement measures have been taken to improve the shock resistance of the structure, and the relevant indicators are able to meet the requirements of the code.

(3) By comparing the calculation results of spatial structural analysis and plane finite element analysis, the calculation results of internal force of structure of spatial structural analysis are closer to reality, while the calculation results of plane finite element analysis for frame-supported columns are conservative and have significantly overestimated the internal forces of transfer beam, which is bound to increase the cross section and reinforcement of members.

(4) In structural analysis of high-rise buildings, infinitely large stiffness in slabs is an important assumption that directly affects the distribution mode of interlaminar shear force between various walls and columns. For big openings in slabs and staggered floors, there will be a larger error in the calculation result using this assumption, so elastic slab assumption should be used based on the actual conditions.

\section{REFERENCES}

[1] Wan Liping. Research on Design of Core Tubes of Super High-rise Buildings [D]. South China University of Technology, 2014.

[2] $\mathrm{Ni}$ Zhigang. Impact of Steel Structure Construction Factors to Be Considered in Design of Super High-rise Mega Composite Structure [A]. The Hong Kong Polytechnic University, Hong Kong Institute of Steel Construction. Proceedings of the Sixth Cross-strait and Hong Kong Conference on Steel and Composite Structures -2010 [C] .The Hong Kong Polytechnic University, Hong Kong Institute of Steel Construction:, 2010: 30.

[3] Chen Liying and Zhang Guoliang. Behavior Analysis in the Casing Process of Super High-rise Steel Tube Concrete Columns [J]. Science and Technology of West China, 2010,17: 9-11.

[4] Fu Changsheng, Zhang Xiaoyong and Zhou Lilang. Torsional Stiffness and Stability of Super High-rise Frame - Core Tube Structure [J] Journal of Building Structures, 2016,02: 26-33.

[5] Zhou Peng. Exploration into the Issues related to Seismic Design of Super High-rise structures [J] Jiangxi Building Materials, 2016,08: 22.

[6] Zhang Hong, Tian Chunyu, Xiao Congzhen, Cao Jinzhe, Li Jianyin and Hao Wei. Studies of vibration Table Test of Tri-tower Connect Super High-rise Structures [J] Earthquake Resistant Engineering and Retrofitting, 2016,02: 44- 51.

[7] Qiu Huanlong, Zhang Shaoliang, Shang Chunyu, Xie Lei and Wang Jinling. Design of Super High-Rise Structure of Dalian Tianan Jinma Center Project [J] Building Structure, 2016, 08: 18-22. 